\title{
THE AUDIO VIDEO OF WEB-BASED COMPRESSION WITH FFMPEG
}

\author{
Haruno Sajati', Asih Pujiastuti², Afrizal Triantoro ${ }^{3}$ \\ Program Studi Teknik Informatika \\ Sekolah Tinggi Teknologi Adisutjipto Yogyakarta \\ harunosajati@stta.ac.id'1, asihpuji@stta.ac.id ${ }^{2}$,izalale95@gmail.com ${ }^{3}$
}

\begin{abstract}
In general, video compression only compresses video files without compressing the audio files in them. This results in the compression process not being maximized.This study discusses the process of compressing video and audio files to get maximum compression. The application built is a web-based video compression software utilizing FFmpeg to do the compression process by breaking down the original video which has a resolution of 720 to 4 files, namely 720, 480, 360, and 240 resolutions. The test is done by comparing the compression results only to video files and compressing to video and audio and there is a 1-2 MB file size difference, whereas when compared to the original file, there is a 5-20 MB size difference. In addition to conducting this test also performed compression testing on different devices and obtained relatively similar results on all devices. Test the image quality on the compressed file obtained the image quality results in the standard video compression below $30 \mathrm{~dB}$ results.
\end{abstract}

Keywords : Web-Based, Video compression, FFmpeg

\section{Latar Belakang Masalah}

File video merupakan data yang memiliki ukuran besar dibandingkan dengan data teks. Karena ukuran yang besar tersebut maka banyak dibuat program untuk mengecilkan ukuran file dengan cara mengompres file video tersebut. Kompresi video merupakan proses pengubahan ukuran dan kualitas file video menjadi lebih rendah. Pada pelaksanaannya selama ini proses kompresi video hanya dilakukan untuk menurunkan kualitas gambar yang terdapat di dalam video tanpa merubah kualitas audio yang terdapat di dalamnya.

Pemanfaatan FFmpeg untuk mengompresi video dengan membagi resolusi menjadi setengah dari resolusi video asli [1]. Proses kompresi terhadap video tersebut tidak menghasilkan hasil kompresi yang maksimal. Pada penelitian ini dilakukan proses kompresi terhadap gambar serta audio yang terdapat didalam file video untuk menghasilkan file kompresi yang lebih maksimal agar didapat ukuran file yang lebih kecil. File hasil kompresi ada 4 resolusi yaitu, 720, 480, 360, dan 240 agar user mendapatkan pilihan kualitas yang akan ditonton pada media player.

\section{Metodologi Penelitian}

Tahapan-tahapan yang dilakukan dalam penelitian ini, sebagai berikut;

1. Studi Literatur

Studi literatur mempelajari literatur dan buku dan jurnal yang berhubungan dengan kompresi data, membangun web, dan video streaming [2],[3],[4].

2. Analisa Dan Kebutuhan Sistem

Analisa yang dibutuhkan pada proses pembuatan serta pengujian web kompresi, kebutuhan utama adalah perangkat yang mendukung program PHP dan FFmpeg untuk melakukan proses kompresi.

3. Perancangan Sistem

Perancangan sistem pada tugas akhir ini menggunakan perangkat pemodelan logik waterfall.

4. Implementasi Sistem 
Implementasi sistem web kompresi video dilakukan untuk melihat apakah program sudah berjalan lancer dan sesuai dengan tujuan awal.

5. Pengujian

Pengujian melibatkan beberapa cara yaitu dengan membandingkan hasil kompresi pada 5 perangkat untuk melihat apakah ada perbedaan ukuran pada setiap perangkat, menghitung rasio kompresi dan presentase penghematan pada hasil kompresi.

\subsection{Prinsip Kerja Sistem}

Flowchart system ini menggambarkan jalannya seluruh proses yang terjadi didalam aplikasi web kompresi sehingga akan terlihat jelas keseluruhan proses yang terjadi, mulai dari pilihan menu apa saja yang ada di dalam web sampai proses kompresi dan streaming video. Proses yang terjadi mulai dari user mengakses web kompresi video akan muncul pilihan menu kompres video dan streaming video. Jika user memilih untuk kompres video maka akan diarahkan untuk memilih video yang akan di kompres, lalu memilih format apa yang akan dipakai.

User melakukan proses kompresi dan menunggu hingga prosesnya selesai sampai ada output laporan bahwa video telah berhasil dikompres. Pada menu streaming video user akan memilih judul video yang akan diputar, setelah memilih maka video bisa diputar, saat proses memutar video ada pilihan kualitas resolusi, user dapat memilih resolusi berapa yang akan ditonton dengan cara memilih salah satu resolusi maka video akan secara otomatis.

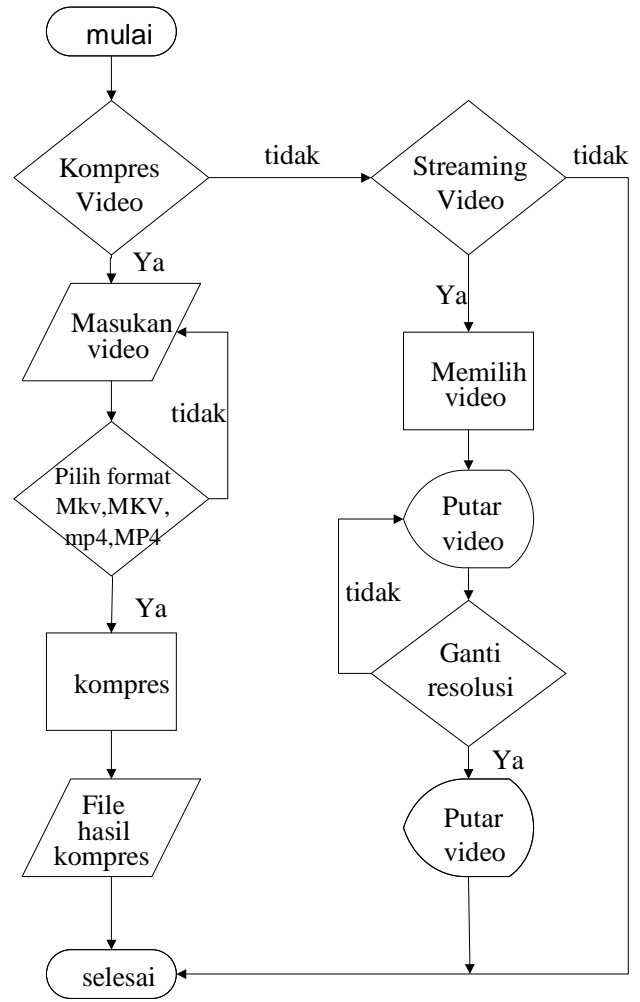

Gambar 1. Flowchart Web Kompresi Video

Dalam pengujian web kompresi ini menggunakan 30 file data uji yang di unduh dari Youtube. Data uji berupa banyak video dengan beragam file size untuk nantinya akan dilihat berapa besar rasio kompresi dan presentase keberhasilan kompresi. Semua data uji di unduh dari Youtube dengan berbagai macam judul dan resolusi video untuk melihat berapa besar rasio kompresi dan presentase penghematan yang dihasilkan dari web kompresi video ini, dapat dilihat pada Tabel 1. 
Tabel 1. Data Uji

\begin{tabular}{|c|c|c|c|}
\hline $\begin{array}{c}\text { Id } \\
\text { Data } \\
\text { Uji }\end{array}$ & Nama Video & Resolusi & $\begin{array}{c}\text { Ukuran Video } \\
\text { Asli (MB) }\end{array}$ \\
\hline 1 & Data_Uji_1.MKV & 720 & 25.5 \\
\hline 2 & Data_Uji_1.MKV & 480 & 16.7 \\
\hline 3 & Data_Uji_1.MKV & 360 & 11.3 \\
\hline 4 & Data_Uji_1.MKV & 240 & 7.66 \\
\hline 5 & Data_Uji_2.MKV & 720 & 29 \\
\hline 6 & Data_Uji_2.MKV & 480 & 19.4 \\
\hline 7 & Data_Uji_2.MKV & 360 & 12.8 \\
\hline 8 & Data_Uji_2.MKV & 240 & 8.17 \\
\hline 9 & Data_Uji_3.MKV & 720 & 26.9 \\
\hline 10 & Data_Uji_3.MKV & 480 & 18.5 \\
\hline 11 & Data_Uji_3.MKV & 360 & 11.5 \\
\hline 12 & Data_Uji_3.MKV & 240 & 7.67 \\
\hline 13 & Data_Uji_4.MKV & 720 & 51.5 \\
\hline 14 & Data_Uji_4.MKV & 480 & 28.2 \\
\hline 15 & Data_Uji_4.MKV & 360 & 17.5 \\
\hline 16 & Data_Uji_4.MKV & 240 & 11.4 \\
\hline 17 & Data_Uji_5.MKV & 720 & 26.4 \\
\hline 18 & Data_Uji_5.MKV & 480 & 19.8 \\
\hline 19 & Data_Uji_5.MKV & 360 & 13.5 \\
\hline 20 & Data_Uji_5.MKV & 240 & 8.63 \\
\hline 21 & Data_Uji_6.MKV & 720 & 52.5 \\
\hline 22 & Data_Uji_6.MKV & 480 & 31.5 \\
\hline 23 & Data_Uji_6.MKV & 360 & 19.7 \\
\hline 24 & Data_Uji_6.MKV & 240 & 13.1 \\
\hline 25 & Data_Uji_7.MKV & 720 & 21.3 \\
\hline 26 & Data_Uji_7.MKV & 480 & 12.48 \\
\hline 27 & Data_Uji_7.MKV & 360 & 10.4 \\
\hline 28 & Data_Uji_7.MKV & 240 & 6.85 \\
\hline 29 & Data_Uji_8.MKV & 720 & 32.4 \\
\hline 30 & Data_Uji_8.MKV & 480 & 18.7 \\
\hline 31 & Data_Uji_8.MKV & 360 & 11.8 \\
\hline 32 & Data_Uji_8.MKV & 240 & 7.79 \\
\hline
\end{tabular}

Dalam kompresi video ini akan digunakan teknik Lossy Compression dimana data hasil kompresi tidak sama dengan data sebelum kompresi namun sudah cukup untuk digunakan, kompresi video memiliki 2 (dua) mode dalam penerimaan yaitu berdasarkan real time atau bisa disebut Dialoque mode, atau tidak real time biasa disebut Retrevial mode dimana user dapat melakukan fast forward dan fast rewind. Dalam penilitian ini digunakan mode yang kedua yaitu Retrevial mode dimana data yang dikompres bersifat tidak real time. 
Perhitungan nilai rasio kompresi dapat dirumuskan pada persamaan[1]:

$$
\text { Rasio Kompresi }=\frac{\text { ukuran file asli }}{\text { ukuran file hasil kompresi }} \text {. }
$$

Persentase penghematan adalah perbandingan antara selisih ukuran file dari sebelum proses kompresidan sesudah proses kompresi dengan ukuran file sebelum proses kompresi. Angka persentasepenghematan menunjukan seberapa besar penghematan yang dicapai dalam suatu proseskompresi, semakin besar persentase maka hasil kompresi semakin baik. Penghitungan nilai persentase penghematan file tersebut menggunakan persamaan [2]:

$$
P P=100 \%-\left(\frac{A}{O} \times 100 \%\right) \quad \text {. . . . . . . . . . . }
$$

Keterangan:

$\mathrm{PP} \quad=$ Presentase Penghematan

A $\quad=$ Ukuran file hasil kompresi (MB)

$\mathrm{O}=$ Ukuran file asli $(\mathrm{MB})$

\section{Hasil dan Pembahasan}

Penjelasan web kompresi video ini terdiri dari 2 menu yaitu menu untuk melakukan proses kompresi video, serta menu untuk melakukan streaming video. Pada halaman kompresi video user dapat melakukan proses kompresi video HD (High Definition) yang akan dikompres menjadi 3 resolusi yaitu 480p, 360p, dan 240p. File yang diupload minimal harus berresolusi 720p. Proses kompresi akan memecah antara video dan audio lalu dilakukan kompresi pada masing-masing file.

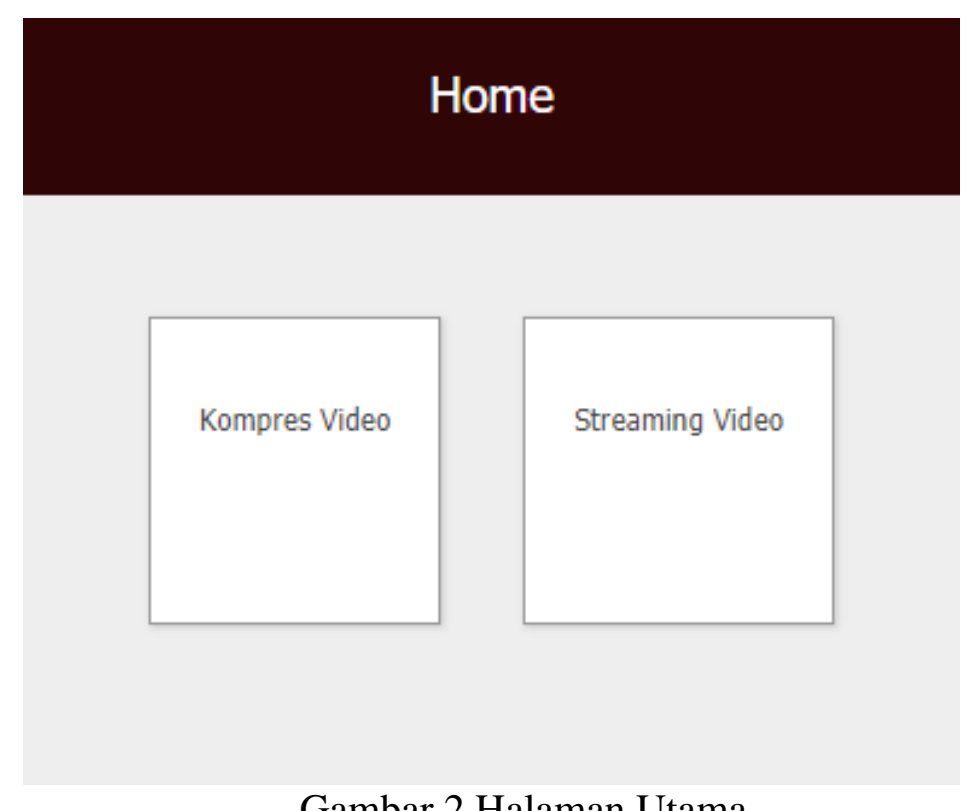

Gambar 2 Halaman Utama

Untuk file audio hanya akan dilakukan kompresi pada 1 kualitas. Setelah melakukan kompresi masing-masing file tersebut akan digabungkan menjadi satu sesuai resolusinya dan akan ditampilkan pada halaman streaming video. Di halaman utama akan disajikan 2 buah menu, yaitu menu kompres dan menu streaming video. Jika user memilih menu kompresi video maka akan diarahkan ke halaman kompresi video, sedangkan jika user memilih menu streaming video maka akan diarahkan ke halaman streaming video. Halaman utama web kompresi video dapat dilihat pada gambar 2. Halaman Kompres video yang merupakan halaman proses kompresi dapat dilihat pada gambar 3, sedangkan halaman hasil kompresi dapat dilihat pada gambar 4 dan untuk gambar 5 dan 6 adalah halaman streaming video. 


\title{
Kompres Video
}

Pilih File Tidak ada file yang dipilih

Pilih Format $\mathbf{v}$

Kirim

Gambar 3 Halaman Kompres Video

\section{Kompres Video}

Pilih File Tidak ada file yang dipilih

\author{
Pilih Format v \\ Kirim \\ Data_UJi_1.MKV Sukses Dikompres
}

Gambar 4 Hasil Output Kompres

Streaming Video

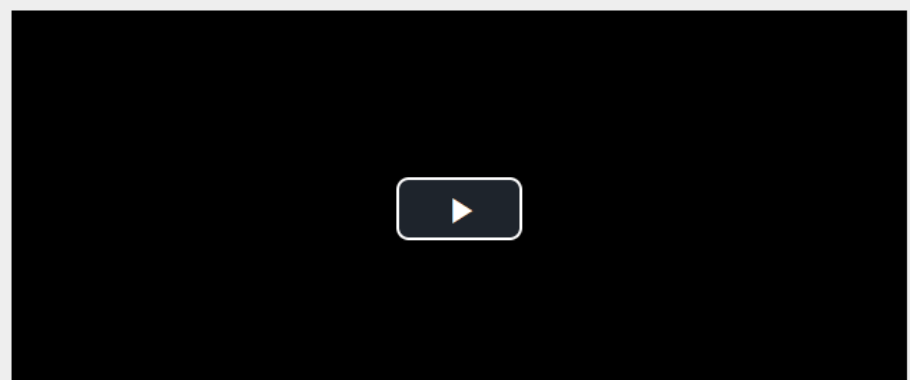

Gambar 5 Halaman Streaming Video 


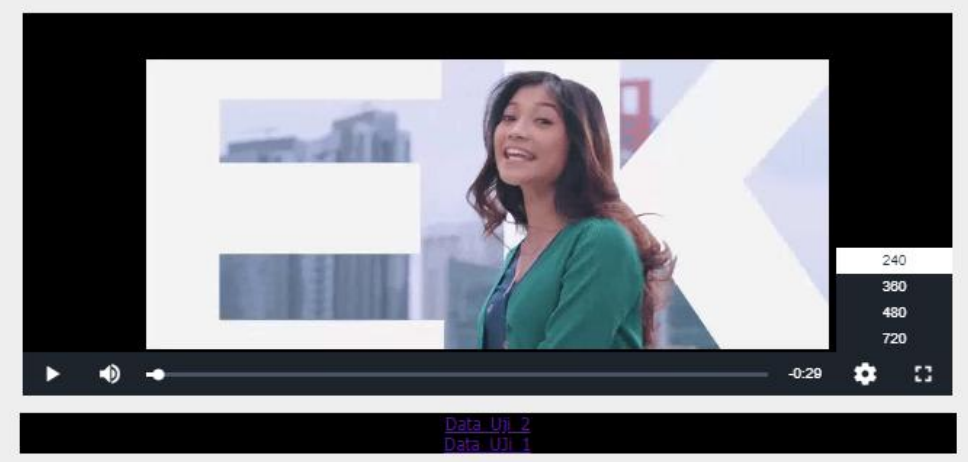

Gambar 6 Halaman Putar Video Dan Merubah Resolusi

Proses pengujian yang pertama dengan melakukan kompresi terhadap file video saja dan dibandingkan dengan hasil kompresi web kompresi video yang melakukan kompresi terhadap file video serta audio yang terdapat didalamnya. Kompresi menggunakan 32 data uji pada tabel 1 dan didapat hasil pada gambar 7 .

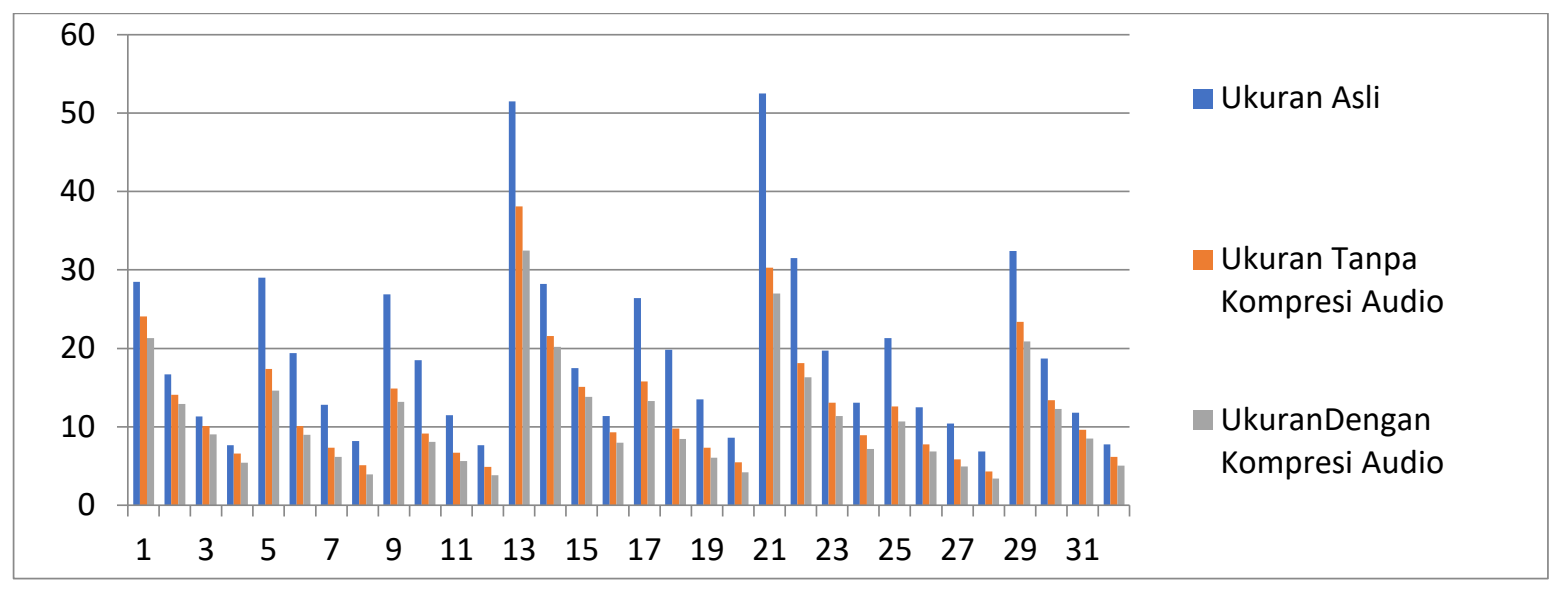

Gambar 7 Grafik Hasil Kompresi

Grafik diatas adalah gambaran kesuluran dari perbandingan 32 data uji, pada tabel 2 hanya ditampilkan beberapa hasil kompresi dan perbandingan antara kompresi file video saja dengan web kompresi file video dan audio yang terdapat didalamnya dapat dilihat hasil kompresi memiliki perbedaan $1-2 \mathrm{Mb}$.

Pengujian selanjutnya adalah pengujian yang dilakukan pada beberapa perangkat untuk melihat apakah ada perbedaan hasil kompresi di berbagai perangkat, berikut ini adalah spesifikasi perangkat yang digunakan untuk pengujian:

Tabel 2 Tabel Spesifikasi Perangkat Pengujian

\begin{tabular}{|c|c|c|c|c|c|c|}
\hline Id & $\begin{array}{c}\text { Nama } \\
\text { Perangkat }\end{array}$ & Prosessor & $\begin{array}{c}\text { RA } \\
\text { M }\end{array}$ & HDD & Graphic Card & $\begin{array}{c}\text { Sistem } \\
\text { Operasi }\end{array}$ \\
\hline A & $\begin{array}{c}\text { Asus } \\
\text { A456U }\end{array}$ & $\begin{array}{c}\text { Intel Core i5 } \\
-7200 \mathrm{U}\end{array}$ & $4 \mathrm{~GB}$ & $1 \mathrm{~TB}$ & $\begin{array}{c}\text { NVIDIA } \\
\text { Geforce } \\
930 \mathrm{MX}\end{array}$ & Windows 10 \\
\hline $\mathrm{B}$ & Lenovo & Intel Core i3 & $4 \mathrm{~GB}$ & $1 \mathrm{~TB}$ & NVIDIA & Windows 10 \\
\hline
\end{tabular}




\begin{tabular}{|c|c|c|c|c|c|c|}
\hline & $\begin{array}{c}\text { Ideapad } \\
320\end{array}$ & $-6006 \mathrm{U}$ & & & $\begin{array}{c}\text { Geforce } \\
930 \mathrm{MX}\end{array}$ & Pro \\
\hline $\mathrm{C}$ & $\begin{array}{c}\text { Lenovo } \\
\mathrm{G} 40\end{array}$ & $\begin{array}{c}\text { Intel Core i5 } \\
-4210 \mathrm{U}\end{array}$ & $4 \mathrm{~GB}$ & $1 \mathrm{~TB}$ & Intel HD & Windows 7 \\
\hline $\mathrm{D}$ & Asus A42F & $\begin{array}{c}\text { Intel Core i3 } \\
\text { M350 }\end{array}$ & $6 \mathrm{~GB}$ & $\begin{array}{c}500 \mathrm{G} \\
\mathrm{B}\end{array}$ & $\begin{array}{c}\text { Intel GMA } \\
\text { HD }\end{array}$ & $\begin{array}{c}\text { Windows 7 } \\
\text { Ultimate }\end{array}$ \\
\hline $\mathrm{E}$ & $\begin{array}{c}\text { Asus } \\
\text { A455L }\end{array}$ & $\begin{array}{c}\text { Intel Core i5 } \\
-4210 \mathrm{U}\end{array}$ & $8 \mathrm{~GB}$ & $\begin{array}{c}500 \mathrm{G} \\
\mathrm{B}\end{array}$ & $\begin{array}{c}\text { NVIDIA } \\
\text { Geforce 820M }\end{array}$ & $\begin{array}{c}\text { Windows 7 } \\
\text { Ultimate }\end{array}$ \\
\hline
\end{tabular}

Gambar 8 merupakan beberapa perbandingan hasil dari web kompresi video pada 5 perangkat dengan spesifikasi yang telah disebutkan. Hasil kompresi dapat dilihat pada grafik diatas bahwa 5 perangkat hasil yang relatif sama jadi spesifikasi perangkat tidak mempengaruhi hasil dari web kompresi video ini. Pengujian berikutnya adalah melakukan perhitungan rasio kompresi dan presentase penghematan pada masing-masing hasil kompresi pada 5 perangkat pengujian. Hasil dari perhitungan dapat dilihat pada grafik 3 dan 4. Dari hasil pengujian pada 32 data uji dan dilakukan pengujian pada 5 perangkat yang berbeda maka dapat diambil kesimpulan bahwa dari semua hasil pengujian didapatkan hasil web kompresi video ini dapat menghasilkan ukuran video yang lebih kecil karena melakukan kompresi pada audio yang tedapat dalam sebuah video.

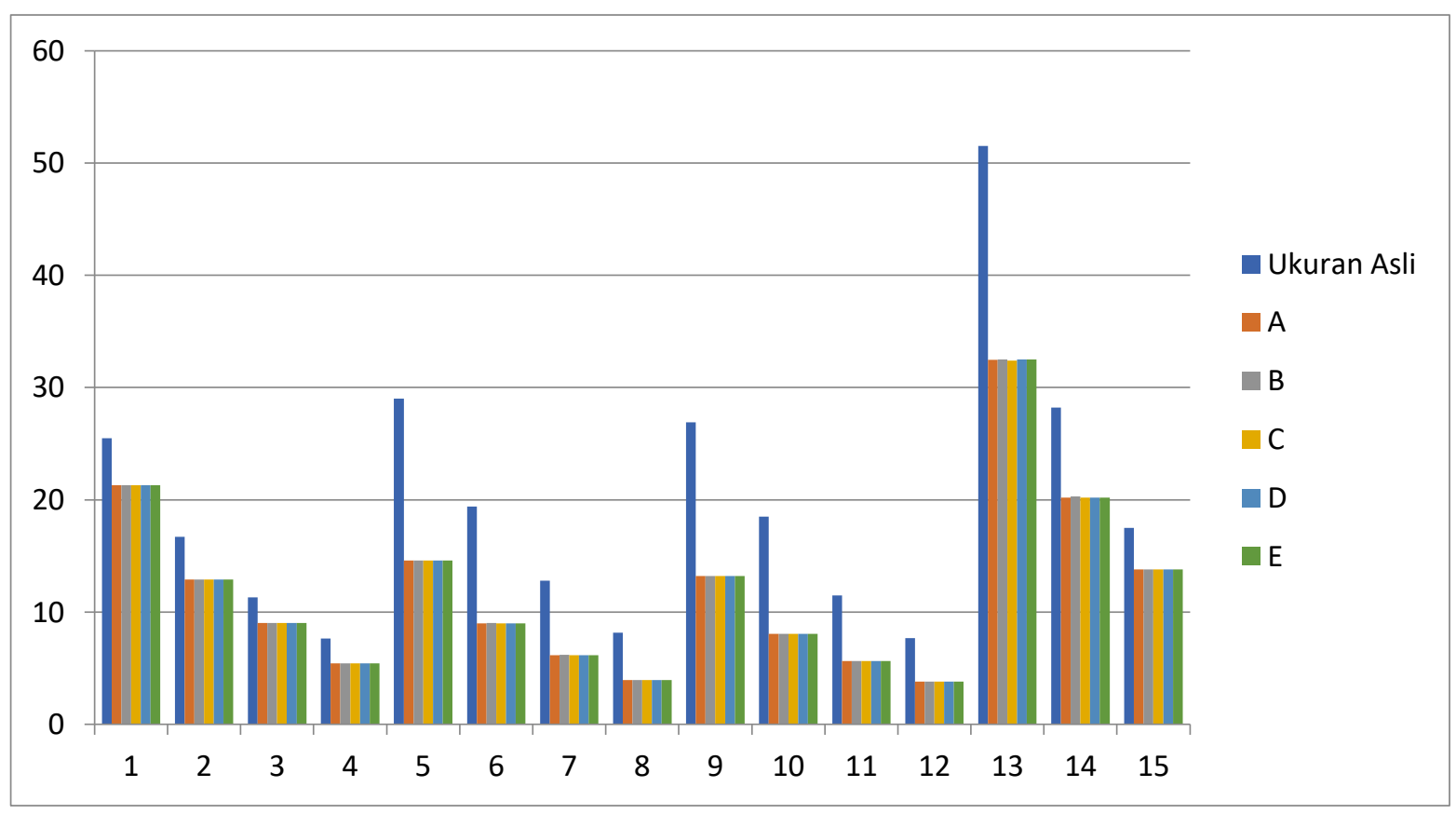

Gambar 8 Grafik Pengujian Web Kompresi

Hasil pengujian menunjukan perbedaan ukuran yang cukup beragam antara proses kompresi pada video saja dan kompresi pada video dan audio yang terdapat didalamnya. Perbedaan ukuran mulai dari 1-2 Mb. Namun jika dibandingkan dengan ukuran file asli maka perbedaan ukuran dapat mencapai $20 \mathrm{Mb}$. Setelah dilakukan semua tahap pengujian file hasil kompresi juga dibandingkan ukurannya dengan file asli yang di unduh dari Youtube. Hal ini dimaksudkan untuk melihat apakah hasil kompresi dari web kompresi video ini menghasilkan ukuran file yang lebih kecil atau tidak. Pada tabel data pengujian semua hasilnya dibandingkan dengan video asli dari Youtube dan didapat kesimpulan bahwa ukuran yang dihasilkan web kompresi video ini jauh lebih kecil dari video asli. 


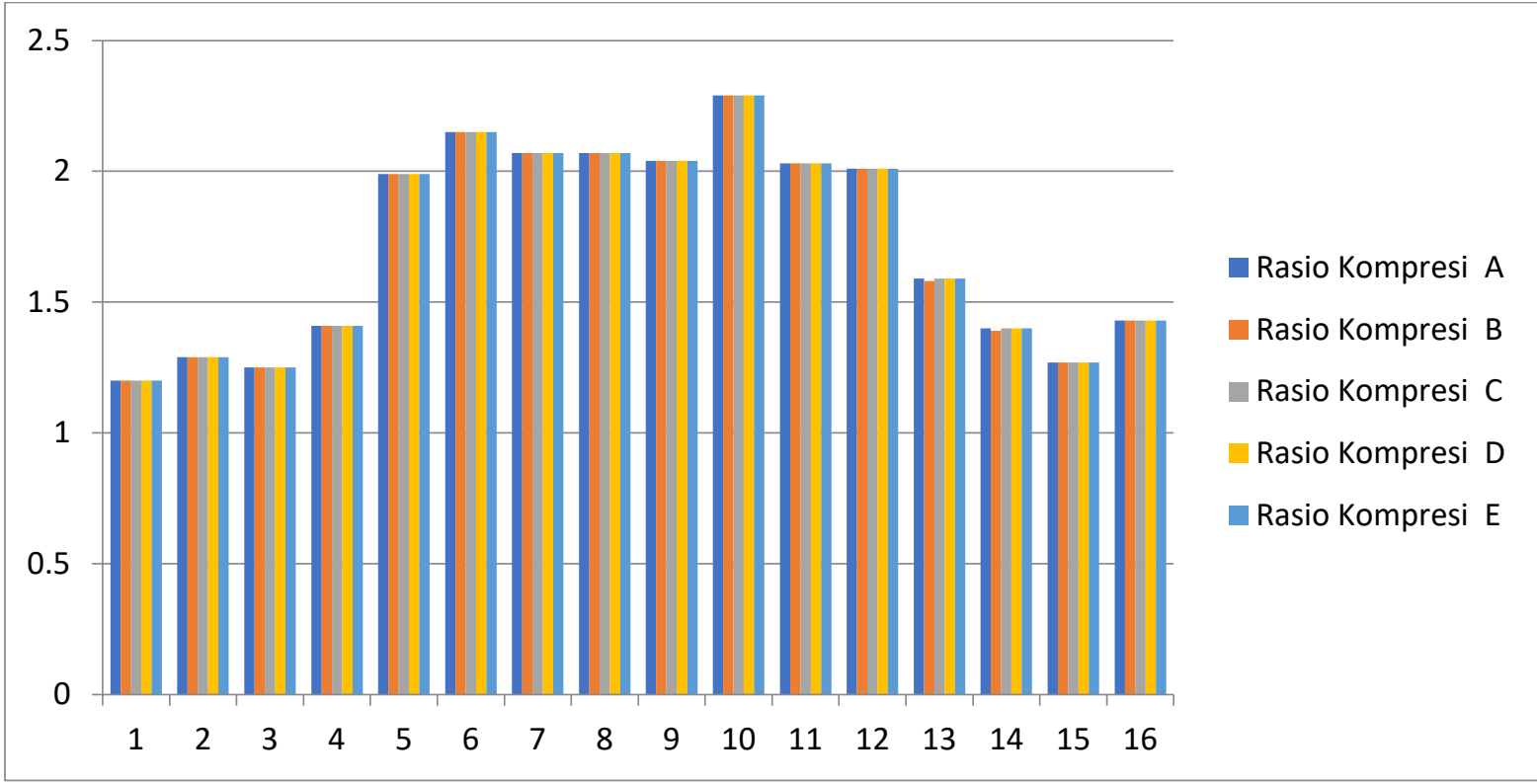

Gambar 9 Grafik Perhitungan Rasio Kompresi

Selain mengamati ukuran file hasil kompresi juga dilakukan pengamatan terhadap kualitas gambar video hasil kompresi, setelah dilakukan pengujian pada beberapa screen capture dari video dapat dikatakan kualitas yang dihasilkan relatif rendah dan tidak memenuhi standar kualitas yaitu $30 \mathrm{~dB}$.

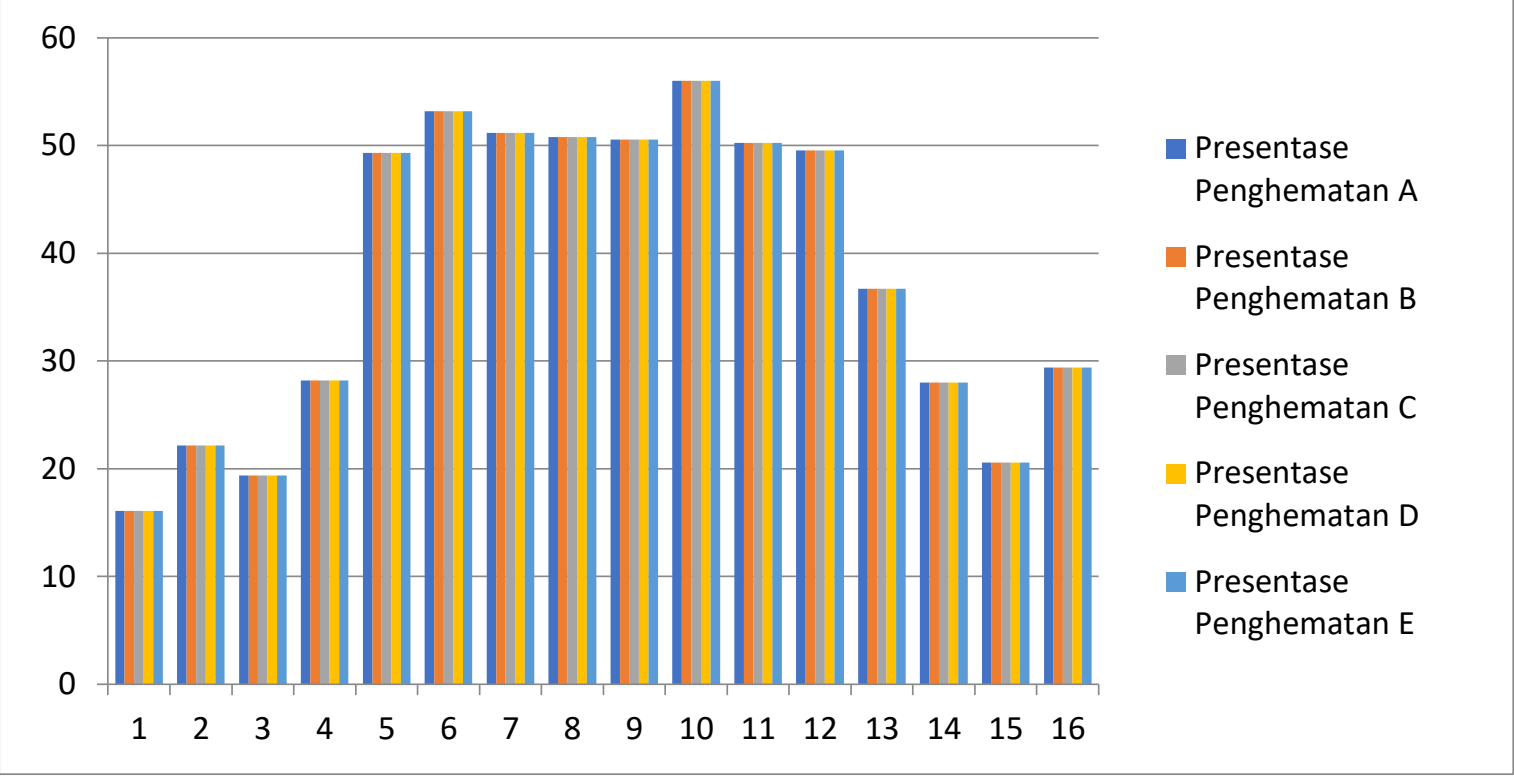

Gambar 10 Grafik Perhitungan Presentase Penghematan

\section{Kesimpulan}

Dari hasil pengujian pada web kompresi video ini dapat diambil beberapa kesimpulan yaitu:

1. Hasil pengujian dan perbandingan antara kompresi video tanpa melakukan kompresi terhadapa audio dan kompresi video dan audio dengan web kompresi ini ternyata didapat hasil dengan melakukan kompresi audio didalam sebuah file video dapat menurunkan ukuran sekitar 1-2Mb.

2. Pengujian dengan membandingkan ukuran video asli dari Youtube dan video hasil web kompresi video menunjukan ada perbedaan ukuran yang cukup signifikan mulai dari 5$20 \mathrm{Mb}$. 
3. Pengujian dengan perangkat yang berbeda menujukan tidak ada perubahan yang signifikan, dan hasil kompresi dari perangkat yang berbeda menunjukan hasil yang relatif sama.

4. Perbandingan antara kualitas video asli dan video hasil kompresi dari web kompresi video ini menunjukan kualitas yang relatif lebih rendah dan tidak memenuhi standar kualitas yaitu $30 \mathrm{~dB}$.

\section{Daftar Pustaka}

[1] Sajati, H., Astuti, Y., \& Octaviana, C. H. (2014). Analisis Pemrosesan Paralel untuk Kompresi Video Pada Jaringan Komputer Berbasis IPV6. Jurnal Angkasa, 6(6).

[2] Badshah, G., Liew, S. C., Zain, J. M., \& Ali, M. (2016). Watermark compression in medical image watermarking using Lempel-Ziv-Welch (LZW) lossless compression technique. Journal of digital imaging, 29(2), 216-225.

[3] Sajati, H. (2018). ANALISIS KUALITAS PERBAIKAN CITRA MENGGUNAKAN METODE MEDIAN FILTER DENGAN PENYELEKSIAN NILAI PIXEL. Angkasa: Jurnal Ilmiah Bidang Teknologi, 10(1), 41-48.

[4] Firmansah, L., \& Setiawan, E. B. (2015). Kompresi Data Audio Lossless Format Flac Menjadi Audio Lossly Format Mp3 Dengan Algoritma Huffman Shift Coding. eProceedings of Engineering, 2(3).

[5] Adji, T. B., \& Nugroho, H. A. (2016, November). Pengaruh Load Balancing Pada Pemrosesan Paralel untuk Kompresi Video. In Conference SENATIK STT Adisutjipto Yogyakarta (Vol. 2, pp. 121-128).

[6] Rimra, I. L., \& Wiharti, W. (2008). Pemanfaatan Jaringan komputer Sebagai aplikasi pendistribusian siaran televisi menggunakan teknologi video streaming. POLI REKAYASA, 3(2), 53-59.

[7] Kelen, W. W., \& Nugraheny, D. (2015). Analisa Pemrosesan Paralel untuk Kompresi dan Dekompresi Data. Compiler, 4(1).

[8] Irawan, W., Dermawan, D., \& Retnowati, N. D. (2013). Perancangan Aplikasi Video Streaming Untuk Pemantauan Air Laut Ketika Terjadi Gempa. Compiler, 2(2).

[9] Hidayat, Z. A., Dermawan, D., \& Retnowati, N. D. (2013). Pengaruh Jarak terhadap Kualitas Gambar dalam Pengiriman Citra Digital melalui Jaringan Wireless pada Kamera Ls Y201. Compiler, 2(2).

[10] Napitupulu, H S., 2012, Analisa Perbandingan Kinerja Teknik Kompresi Citra Menggnakan Metode JPEG dan WAVELET Multi Variabel. http://lontar.ui.ac.id/file?file=pdf/metadata20308365.pdf, diunduh pada tanggal 20 Maret 2014. 